\title{
Using Waste Heat for Sustainable Manufacturing Based on the Example of a Conventional Industrial Bakery
}

\author{
K. Schwabe, M. Walsdorf-Maul, F. Schaudienst, and F. U. Vogdt
}

\begin{abstract}
The European Union has set a target to reduce carbon dioxide emissions by 2020. It is not enough to change to low $\mathrm{CO}_{2}$ emitting energy sources, to increase the efficiency of energy conversion and to accelerate the expansion of renewable sources, but it also needs to increase the energy efficiency. The utilization of residual heat still enjoys significant economic potential, which has not yet been utilized. Corresponding to the second law of thermodynamics each machine produces heat. This heat does not always contain enough energy for a second use. Therefore studies in Germany expect that a temperature level about $60^{\circ} \mathrm{C}$ is necessary to use waste heat.
\end{abstract}

Index Terms-Waste heat, sustainable manufacturing, reduction of $\mathrm{CO}_{2}$, energy efficiency, life cycle assessment.

\section{INTRODUCTION}

As a result of climate change and $\mathrm{CO}_{2}$ reduction the type of energy source and the responsible use of energy are questioned. In this context there is not only the demand of decreasing $\mathrm{CO}_{2}$ emissions and using renewable energies but also increase in efficiency of energy using. Therefore using consequently waste heat might have a considerable potential for the future. At the same time the produced waste heat has a direct impact on climate change. Latest studies show that waste heat has a share of $3 \%$ of global warming potential.

Considering different process chains for manufacturing a product waste heat is created in industry and crafts. Often the energy of waste heat is not used. In Germany it is assumed that waste heat for temperatures between $60^{\circ} \mathrm{C}$ and $140^{\circ} \mathrm{C}$ has a portion of $6 \%$ and for temperatures about $140^{\circ} \mathrm{C} 12 \%$ of the industrial final energy demand [1]. In using waste heat there are different problems and obstacles like:

\section{1) Structural and local:}

- Missing heating demand in the neighborhood

- Discrepancy of time and the temperature between the produced heat and demand

2) Safety and profitability of production:

- Individual assessment, reliability

3) Information:

- Lack of knowledge, prejudices

4) Legal and administrative

Manuscript received January 16, 2013; revised March 22, 2013.

The authors are with University of Technology, Berlin (e-mail: kathleen.schwabe@tu-berlin.de, manuela.walsdorf-maul@tu-berlin.de, falk.schaudienst@tu-berlin.de, bauphysik@tu-berlin.de).

\section{- Bureaucracy, requirements for core business}

According to national practice these problems and obstacles are differently solved. In Germany on the one hand there are promotions of energy measures and on the other hand various research initiatives. For example „Eneff-Stadt“", in which the energetic integration of neighborhoods is investigated and developed, detecting and eliminating structural and local problems.

The analyzed sample is a bakery as a SME (small and medium enterprises). In Germany there are 14500 SME bakeries, this means one bakery supplies for 5600 inhabitants in total. In bakeries the largest waste heat producer is the heat oven with temperatures up to $320^{\circ} \mathrm{C}$ [2]. Fig. 1 shows the energy distribution of an oven. In total $36 \%$ of energy is useful energy. The other portions are made by steam, surface and flue gas losses. Moistening of baked products at the oven causes steam losses, thermal radiation surface losses and heating with gas flue gas losses. It raised the question how the energy loss of the oven can be used.

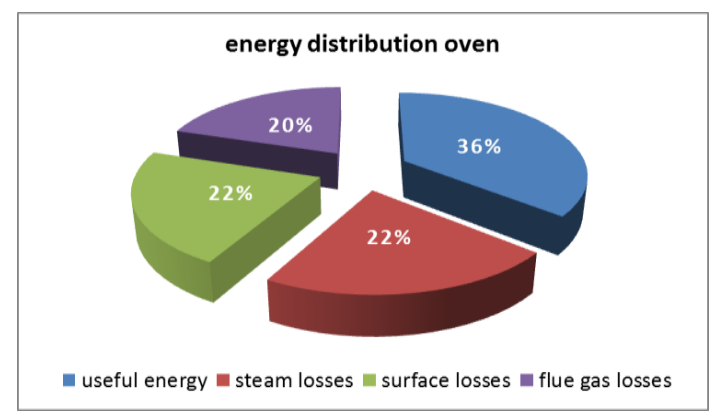

Fig. 1. Energy distribution of an oven.

\section{INVESTIGATION}

\section{A. Overview}

Bakeries need among the most energy of crafts. Therefore, energy costs in bakeries are approximately $2.9 \%$ of the production costs. Half of them relates to the energy source of natural gas. The portion of electricity is about $29 \%$. The electricity use is distributed in:

1) Lighting systems: $5 \%$

2) Heating infrastructure: $2 \%$

3) Water systems: $10 \%$

4) Process heat: $45 \%$

5) Refrigeration systems: $30 \%$

6) Ventilation: $5 \%$

7) Production machines: $2 \%$

8) Other: $1 \%$

Processing raw material only electrical energy is 
consumed. The raw materials are generally stored in silos and transported by pneumatic conveying. In the conveying lines screens are often integrated which are necessary for separating impurities and for flour are loosening. In most bakeries this process demands less than $0.05 \%$ of the total electrical energy demand.

Before starting with the baking process also heat and electrical power is needed. Depending on the product, the dough pieces are kept for 30-90 minutes at humidity of $60-90 \%$ and with temperatures of $30-40^{\circ} \mathrm{C}$. This process might be interrupted by a temperature decrease or delay, so that a pre-production becomes possible. Then dough pieces are slowly thawed and brought to fermentation temperature. Highest possible capacity and low idle time of equipment are important for the efficiency of a bakery.

In a bakery the ovens have the greatest energy consumption. In general, in a batch process 4-5 tons of bread per day are produced by using deck ovens or rack ovens. At higher production capacity continuously fed ovens (tunnels) are preferred. Electricity, gas or oil are used as an energy source to heat the oven. Depending on the product and baking phase temperatures of $200-300^{\circ} \mathrm{C}$ are required. Less than $5 \%$ of the produced heat in the baking process is needed for the transformation.

Ovens are often operated at too high temperatures or too large steam addition. Through the use of measuring and control equipment, such as steam aperture and vapor control valves, the minimum requirement is determined for each product and can be adjusted during the baking process.

At the end of process to increase the shelf life and to prevent "staling" (retrogradation) cooling is used.

\section{B. Energy Indicators}

For bakeries the processed flour is used to define the energy requirement as production-specific size. Due to the different sizes of company and product lines there are considerable variations. The indicators are to be understood as a guide. Table I shows the indicators for energy use in bakeries.

TABLE I: ENERGY INDICATORS

\begin{tabular}{lll}
\hline \hline description & code & unit \\
& & \\
\hline Total energy consumption mix bread & 73 & $\mathrm{kWh}_{\mathrm{el}} / \mathrm{t}_{\text {flour }}$ \\
& 641 & $\mathrm{kWh}_{\mathrm{th}} / \mathrm{t}_{\text {flour }}$ \\
\hline Total energy consumption bun & 104 & $\mathrm{kWh}_{\mathrm{el}} / \mathrm{t}_{\text {flour }}$ \\
\hline Total energy consumption toast & 350 & $\mathrm{kWh}_{\mathrm{th}} / \mathrm{t}_{\text {flour }}$ \\
\hline Total energy consumption pastry & 95 & $\mathrm{kWh}_{\mathrm{e}} / \mathrm{t}_{\text {flour }}$ \\
& 569 & $\mathrm{kWh}_{\mathrm{th}} / \mathrm{t}_{\text {flour }}$ \\
\hline \hline
\end{tabular}

\section{Energy Saving by Using Heat Waste}

In bakeries the hot water demand for the production and purification is very high. By using waste heat for water heating but also for heating private areas, offices, sales areas etc. heat recovery could save a lot of energy. Fig. 2 shows a scheme of using waste heat for separate streams at the oven.

For using waste heat the level of temperature plays a role. It is much easier to use the waste heat for warm water if the temperature level is about $120^{\circ} \mathrm{C}$. In cases with a temperature level of $30^{\circ} \mathrm{C}$ a heat pump would be required. In our calculated and investigated example of a bakery the level of temperature is about $120^{\circ} \mathrm{C}$. A further point is the time difference between supply and demand. When heat supply and consumption are not consistent over production time, it is advisable to use a buffer tank. The buffer stores the heat temporarily and releases it when needed again.

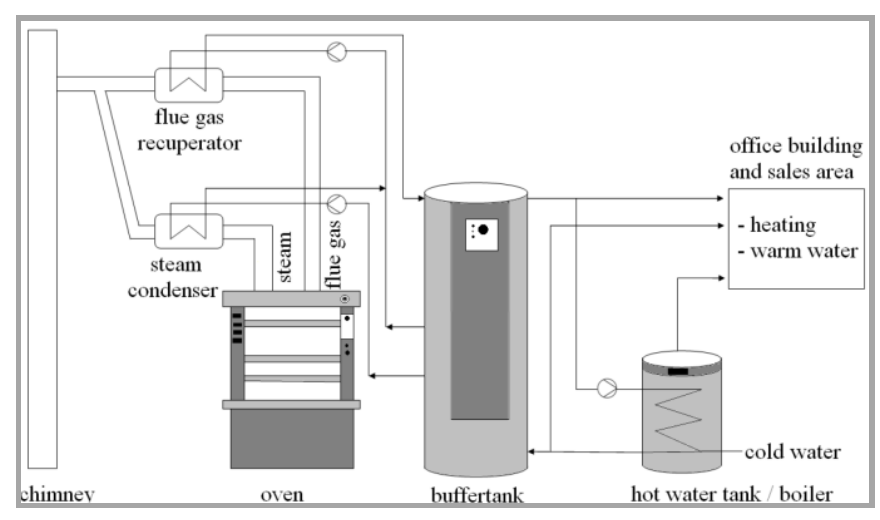

Fig. 2. Scheme of using waste heat.

\section{Exemplary Bakery}

This paper deals with the calculation model of an exemplary bakery shown in Fig. 3 with a net floor space about $291 \mathrm{~m}^{2}$. It is divided in two buildings complexes: $194 \mathrm{~m}^{2}$ for the production hall, $97 \mathrm{~m}^{2}$ for office building and sales area in total. This paper deals with the comparison between district heating, using a gas condensing boiler and using waste heat.

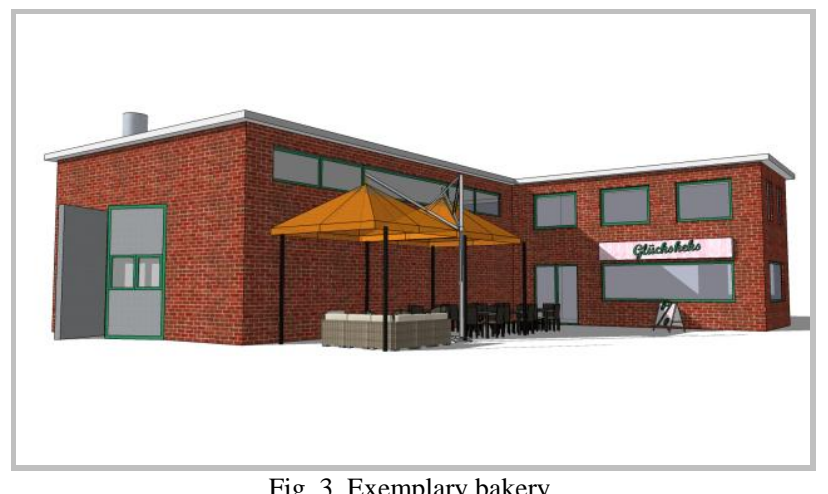

\section{E. Energy Demand Calculation}

According to German standards for residential and non-residential buildings - DIN V 18599 - the energy requirement is calculated with the software program 'Dämmwerk' of KERN Ingenieurkonzepte [3]. The warmth-transferring surface of the calculation model shall be $980 \mathrm{~m}^{2}$. The calculation model of the building is described below. The primary energy demand is calculated by using the German standard DIN V 18599-1 and is shown in Equation (1) [4]:

$$
Q_{p}=\sum\left(Q_{f, j} \cdot \frac{f_{p, j}}{f_{H S / H I, j}}\right)
$$

With $Q_{f, j}$ for final energy demand, $f_{p, j}$ for primary energy factor and $\mathrm{f}_{\mathrm{HS} / \mathrm{HI}, \mathrm{j}}$ as a conversion factor. 


\section{F. Life Cycle Assessment}

To compare the variants ecologically the environmental aspects are calculated based on a life cycle for one year during the operational phase. The chosen quantifiable impacts are annual global warming potential (GWP), acidification potential (AP), eutrophication potential (EP) and the input of renewable and not renewable primary energy (PEI). For the calculation of the Life Cycle Assessment the ecological factors based on the program LEGEP [5] are used.

\section{RESULTS - ENVIRONMENTAL EXPENSES AND EFFECTS}

A bakery has a very high energy demand and the oven needs much energy for the production. However the oven passes a lot of energy to the room, this energy is not used. Based on this knowledge it is very important to use the waste heat. The reduction of the energy demand has a big influence on the environmental expenses and effects throughout the period of operation of the building. Fig. 3 shows the primary energy input renewable for the possibilities using a gas condensing boiler or a district heating for the cases not using the waste heat and this figure also shows the input by using the waste heat.

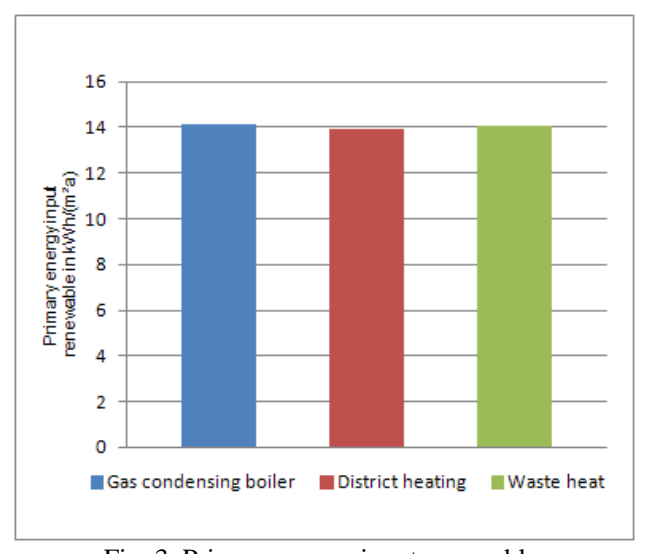

Fig. 3. Primary energy input renewable.

The primary energy input renewable for using gas or district heating is very low. By using the waste heat of the oven the only one user of energy is the electric power. Nearly only the electric energy has a part of the primary energy input renewable. Due to this fact the primary energy input renewable is nearly the same for all technologies - with and without waste heat utilization.

Fig. 4 shows the primary energy input non-renewable.

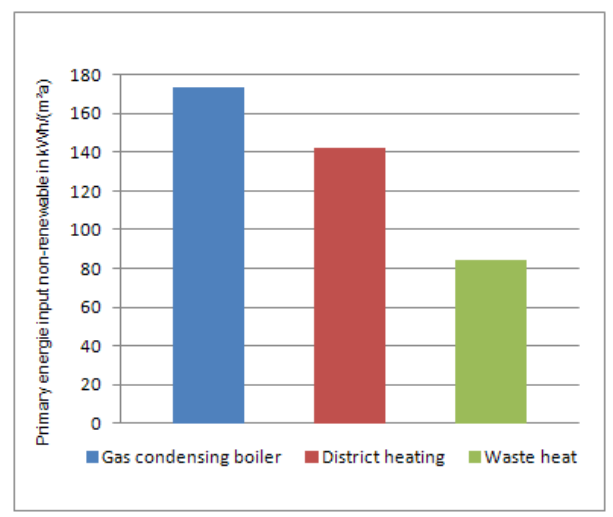

Fig. 4. Primary energy input non-renewable.
The primary energy input non-renewable is much lower for using a district heating compared to the use of a gas condensing boiler. If the waste heat will be used the primary energy input non-renewable can be reduced nearly to the half.

The global warming potential is shown in Fig. 5.

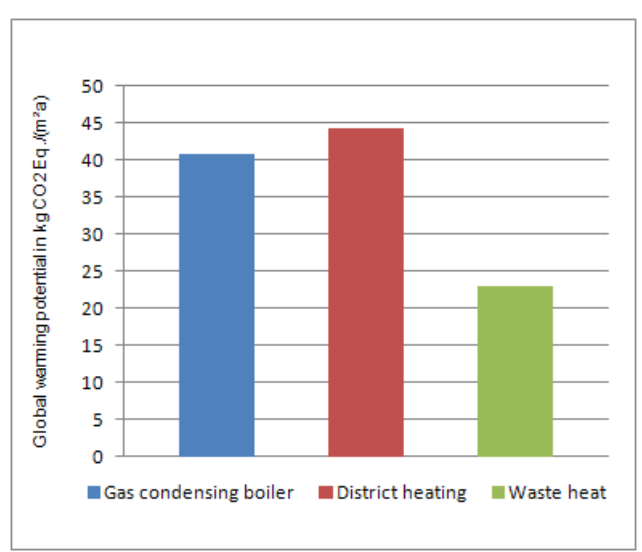

Fig. 5. Global warming potential.

For the use of district heating the global warming potential is higher as for using a gas condensing boiler. By using the waste heat of the oven the potential can be highly reduced. Fig. 6 shows the acidification potential.

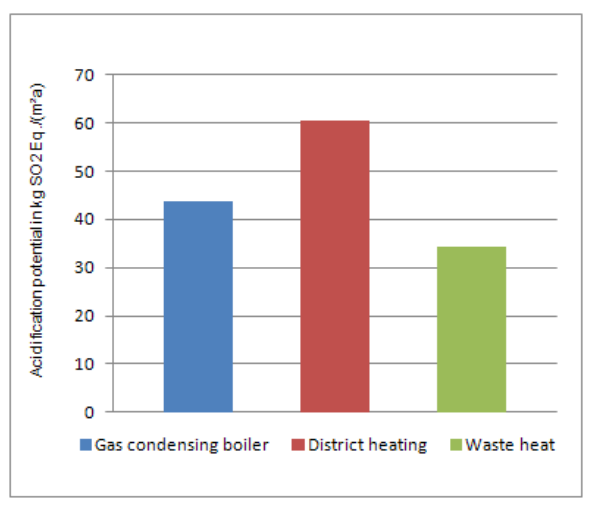

Fig. 6. Acidification potential

The acidification potential is very high for using district heating. By using the waste heat of the oven the potential can be reduced. The same result can be recognized for the eutrophication potential - this is shown in Fig. 7.

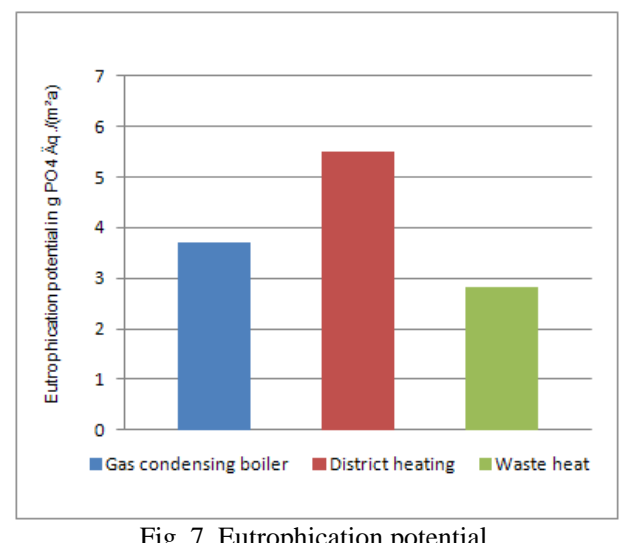

To summarize without using the waste heat of the oven it is more ecological to use the gas condensing boiler. If the waste 
heat will be used for the conditioning of the inner climate, the environmental expenses and effects can be highly reduced.

\section{CONCLUSION}

This investigation shows that in the ecological view it make sense to use the waste heat for heating and warm water heating. All three investigated impacts, global warming, acidification and eutrophication potential are reduced by half compared to the conventional heating systems. A closer look to the conventional heating systems shows that district heating has a better primary energy input for non-renewable but also a worse value for the global warming potential, acidification potential and eutrophication potential.

To make statement about investigations of the whole life cycle it is necessary to calculate life cycle costs. Therefore the final energy might be interested for the building owner to estimate the running costs of the building. The choice of the building technology depends on the aims. However, the weighting of impact indicators is still difficult.

In total it is obvious that using waste heat is not only forward-looking but a possibility to save energy and to reduce the environmental expenses and effects and $\mathrm{CO}_{2}$ emissions.

\section{REFERENCES}

[1] M. Pehnt, "Die Nutzung industrieller Abwärmetechnisch-wirtschaftliche Potenziale und energiepolitische Umsetzung (Using waste heat - technical economic potentials and political energy conversion)," Heidelberg, Karlsruhe 2010.

[2] Bayerisches Landesamt für Umweltschutz: Bäckerhandwerk, Energie sparen - Kosten senken! Augsburg 2003.

[3] DÄMMWERK 2013. Software for building physics. Kern Ingenieurkonzepte.

[4] DIN V 18599-2: 2011, Energy efficiency of Buildings: Calculations of the net, final and primary energy demand for heating, cooling, ventilation, domestic hot water and lighting

[5] LEGEP Software for life-cycle planning of the WEKA MEDIA GmbH \& Co. KG in Version 2.4.598.

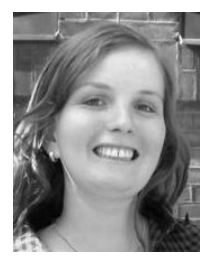

Kathleen Schwabe has received the M.Sc. degree, she is a scientific employee at Technische Universität Berlin at the chair of Building Physics and Building Constructions since September 2012.

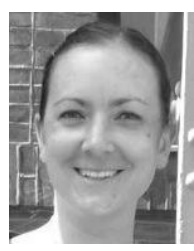

Manuela Walsdorf-Maul is a scientific employee at Technische Universität Berlin at the chair of Building Physics and Building Constructions since 2007. Since $12 / 2011$ she is a technical expert for energetic building design.

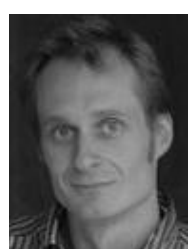

Falk Schaudienst has received the M.A. degree, he is a scientific employee at Technische Universität Berlin at the chair of Building Physics and Building Constructions since 2008.

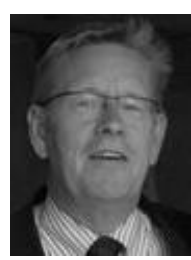

Frank U. Vogdt is the head of the section (Univ.-Prof.) of the chair of Building physics and Building Constructions at Technische Universität Berlin since 2007. 